\title{
Поддержка контрактного производителя - важный шаг на пути к технологической независимости
}

\author{
Рассказывает заместитель директора ООО "TEXHOTEX" \\ В. Д. Семёнов
}

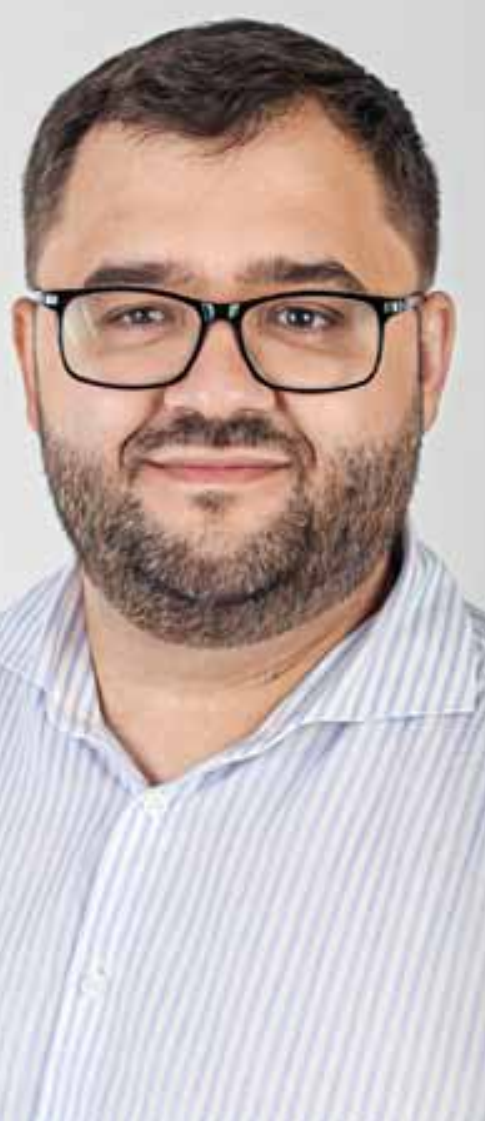

Компания "TЕХНОТЕХ», расположенная

в г. Йошкар-Ола, в прошлом году отметила

20-летний юбилей, однако ее история началась намного раныше, в те годы, когда в Республике Марий Эл (тогда Марийской АССР) только формировалась радиоэлектронная промышленность. Сегодня предприятие обладает технологиями, позволяющими изготавливать на собственном производстве компании широчайший спектр печатных плат до 6 класса точности, включая гибкожесткие и СВч-платы. Кроме того, "ТЕХНОТЕХ" оказывает услуги контрактной сборки, а с 2012 года выпускает собственные базовые материалы для печатных плат - фольгированные стеклотекстолиты. Об истории компании и ее возможностях,

о Стратегии развития электронной промышленности РФи вопросах освоения гражданской продукции оборонными предприятиями, о потребностях производителей печатных плат и идеях развития этого направления в России мы поговорили с заместителем директора ООО "ТЕХНОТЕХ" Владимиром Дмитриевичем Семёновым.

Владимир Дмитриевич, расскажите, пожалуйста, как была создана компания "TEXHOTEX". Что легло в ее основу?

История компании "ТЕХНОТЕХ» УХодит своими корнями еще в военные годы. Во время Великой Отечественной войны в Йошкар-Оле заработал Союзный завод № 297, который принял на свою площадку ряд эвакуированных предприятий из Ленинграда, Москвы, Одессы и казани. Завод активно развивался, превращаясь не просто в градообразующее, а в республикообразующее предприятие. Именно он стал основой развития радиоэлектронной промышленности в Марий Эл. Сейчас он называется АО «Марийский машиностроительный завод" и входит в состав Концерна ВКО «Алмаз-Антей».

Вокруг ММз создавалось множество предприятий. В 1970 году было принято решение развивать на заводе направление производства печатных плат. Сначала оно было организовано на одном из участков цеха № 6 Мм3, но вскоре был открыт отдельный цех № 49, ставший базовым производством многослойных печатных плат Министерства радиопромышленности СССР, где изготавливалась продукция для большого количества предприятий Поволжья. Основную долю 
составляли печатные платы для средств ПВО. В дальнейшем на базе этого производства был создан завод "Новатор", на территории которого мы находимся сейчас.

В 1990-х завод "Новатор" перешел в частные руки - его акции были распределены между сотрудниками. Однако, оказавшись без традиционных заказов от производителей зенитных комплексов, со временем предприятие стало приходить в упадок. Тогда нынешний директор ООО «ТЕХНОТЕХ" Дмитрий Владимирович Семёнов нашел инвесторов, которые заинтересовались созданием на базе данного производства обновленного предприятия - производителя печатных плат, и они выкупили цех у его владельцев.

Так появилась компания "TEXHOTEX", которая в прошлом году отметила 20-летний юбилей, а самому производству печатных плат в том же 2020-м исполнилось 50 лет. За два десятилетия на предприятии было проведено множество реформ - как технических, таки кадровых, и на сегодняшний день "TЕXHOTEX", по нашему мнению, является одним из лидеров рынка в своем сегменте.

\section{Как бы вы охарактеризовали сегмент, в кото- ром работает "ТЕХНОТЕХ"?}

Исторически основная продукция нашей компании - это печатные платы военного назначения. Однако данной областью наша деятельность не ограничивается. Мы освоили контрактную сборку печатных узлов, и она также является важным для нас направлением.

Хотя мы действительно чувствуем себя наиболее комфортно на рынке военной техники, мы видим ту активность, которая сейчас имеет место в секторе гражданской электроники и продукции двойного назначения, те меры, которые руководство страны предпринимает для того, чтобы поднять данный сектор. Мы хотели бы принимать непосредственное участие в этом процессе. И здесь наша цель - не только и не столько получить прибыль, сколько оказать посильную помощь и нарастить потенциал, в том числе свой собственный.

С вашей точки зрения как производителя печатных плат, насколько значимы отличия гражданского рынка от военного?

Отличия колоссальны, и они проявляют себя во всем - от общих подходов к управлению предприятием и планированию производства до организации техпроцессов.
Начнем с того, что оборонные предприятия совершенно не готовы к работе на открытом гражданском рынке. Они мыслят абсолютно другими категориями - плановыми заказами и жесткими требованиями стандартов. Они не знают принципов рынка, не умеют договариваться так, как это необходимо в рыночной среде.

У них, как правило, нет дизайнеров упаковки, которые должны сделать продукт привлекательным в условиях рынка. Да, допустим, они разрабатывали много лет упаковку для своей продукции, но как это выглядело? В стандарте сказано, что ящик должен быть из березы, а не из сосны, потому что сосна дает смолу, которая может на-

\section{Отпичия гражданского рынка от военного проявляют себя во всем - от общих подходов к управлению предприятием и планированию производства до организации техпроцессов}

нести вред аппаратуре. И задача ограничивалась тем, чтобы выполнить подобные требования. Кто-нибудь задумывался о том, что эта упаковка желательно, коробка, а не ящик - должна бросаться в глаза на витрине на фоне коробок с продукцией конкурентов? Конечно, нет. И мгновенно эта ситуация измениться не может.

То же касается продвижения продукции. У многих оборонных предприятий нет не то что специалистов по маркетингу, способных продвигать продукцию, скажем, с помощью Интернета. Уних нет даже доступа в Интернет. Он заблокирован по соображениям безопасности.

Всё это приводит к тому, что задача диверсификации ОПК, увеличения доли гражданской продукции в общем объеме производства оборонных предприятий для многих из них поначалу оказалась очень сложной.

И я считаю, что с утверждением новой отраслевой стратегии ситуация коренным образом изменилась в лучшую сторону. Если в 2016 году предприятиям, фактически, сказали, что привычный для них гособоронзаказ сильно сокращается, и им необходимо будет обеспечивать себя путем производства продукции для гражданского рынка, то новая стратегия говорит не столько о том, что делать, сколько о том, как делать. Она - результат того, что в 2018-2019 годах правительство 
обратило внимание на отрасль, стало разбираться, что в ней происходит, какие задачи должны быть поставлены и какие решения необходимы. В итоге стали появляться различные варианты, например сквозные проекты - давайте поможем конечному заказчику, а уже он поможет остальным вниз по кооперации. Или поддержим субсидиями разработчиков: пусть они будут создавать больше решений, которые привлекут инвесторов, они подхватят эти проекты, и всё начнет развиваться. То есть это не способ просто сохранить военные предприятия, а инструменты, направленные на то, чтобы развивать бизнес с частными инвестициями, сделать нашу отрасль привлекательной для инвесторов и "раскрутить маховик» отечественной электроники как части рынка.

Но ведь реализация этой стратегии всё равно в большой степени опирается на оборонные предприятия, далеко не только на частные.

Здесь важен следующий момент. Когда частный заказчик приходит на военный завод со своим продуктом за мощностями - это очень хорошая практика. Он использует завод в качестве производственной площадки, а все вопросы бизнес-планирования, продвижения и продаж оставляет за собой. В этой модели каждый делает то, что лучше всего умеет.

\section{Инвестищи в расширение} производства печатных плат дия гражданского сектора - это серьезная нагрузка для большинства российских производителей

Но проблема в том, что, к сожалению, за редким исключением частные заказчики не имеют прямого доступа к производствам оборонных предприятий, потому что последние входят в состав концернов - замкнутых структур. Сейчас, с началом реализации новой стратегии, появились проекты, работающие по модели государ ственно-частного партнерства, пусть пока они единичные и еще довольно сырые.

Вы рассказали о вопросах управления, а в чем отличия военных и гражданских производств с точки зрения техпроцессов?

Если кратко, отличие в том, что военное производство тяготеет к универсальности, а гражданское - кспециализации. Любой производитель мечтает о том, чтобы выпускать миллионными тиражами одно и то же изделие. И в гражданском, особенно потребительском, секторе, это вполне возможно. В Китае, где в одном городе может насчитываться несколько тысяч компаний - производителей печатных плат (напомню, что во всей России лишь порядка 50 таких компаний, активных на рынке), отдельный такой производитель может изготавливать только, предположим, двусторонние платы с одним единственным типом покрытия, с одним типом маски и из одного базового материала. Более того, он может непрерывно выпускать только один вид изделий, например только одну из нескольких плат в каком-нибудь бытовом приборе. А производство других плат заказчик будет размещать на других производствах.

В военном секторе такое невозможно. Во-первых, там нет массового, поточного производства; серии сравнительно небольшие, и отдельные типы изделий не смогут "прокормить" производителя. Во-вторых, сам заказчик хочет, чтобы все нужные ему платы были сделаны на одной площадке. Это значит, что производитель печатных плат для оборонного сектора вынужден быть универсальным, он должен обладать как можно более широким спектром технологий, быть способным изготовить плату практически любого типа.

Стоит ли это понимать так, что производитель, исторически работавший с оборонными заказами, априори готов к любому заказу из гражданской области, а обратное неверно?

В том-то и дело, что нет.

Да, с точки зрения технологических возможностей такой производительготов сделать плату практически любой сложности. Примером этому служит то, что мы в прошлом году успешно изготовили образцы сложнейших печатных плат систем хранения данных для лидеров отечественного рынка. Но изготовить образец - это одно, а запустить экономически целесообразное серийное производство - совсем другое

Думаю, практически в любой области крупносерийное оборудование отличается от того, которое предназначено для единичного и мелкосерийного производства. Вообще говоря, оно обеспечивает высокую производительность и низкую себестоимость продукции ценой той самой универсальности, которая характерна для оборонного сектора. 
При этом производство печатных плат обладает своей спецификой. Оборудование для поверхностного монтажа или для механообработки можно приобрести даже под конкретный достаточно большой заказ, при наличии опыта быстро запустить, а затем без проблем продать. Более того, такое оборудование можно даже брать в аренду.

С оборудованием же для изготовления плат это невозможно. Эти процессы отличаются высокой наукоемкостью, требуют значительного объема работ по пусконаладке, для них нужна достаточно сложная инфраструктура: специальные помещения, очистные сооружения и т. п. А продать такое оборудование сложно из-за ограниченности рынка. Поэтому инвестиции в расширение производства для гражданского сектора достаточно велики и сопряжены с рисками, и для большинства российских производителей, которые представляют собой сравнительно небольшие частные компании, такие как наша, это серьезная нагрузка.

И теперь представьте: приходит на наше предприятие заказчик, включенный в цепочку сквозного проекта. У него есть бюджет на изготовление печатных плат. Но нас этот бюджет не устраивает: мы не можем на наших универсальных процессах обеспечить достаточно низкую себестоимость, чтобы получить на этом заказе прибыль. Что сделает заказчик? Очевидно, уйдет в Азию. В результате та финансовая помощь от государства, которая в рамках сквозного проекта должна была содействовать развитию отечественной промышленности, уходит за рубеж.

Что должно измениться, чтобы таких ситуаций не возникало?

Во-первых, нужна целевая помощь производителям, а во-вторых-инструменты, обеспечивающие определенные гарантии наличия заказов и, как следствие, снижающие риски невозврата инвестиций в расширение производства.

Хотя те меры поддержки отрасли, которые за последнее время были введены Минпромторгом России, уникальны для нашей страны и с ними связано много надежд, они, к сожалению, сосредоточены только на разработчикахи производителях конечной продукции, а такие участники процесса, как контрактные производства, оказались ими не охвачены. Здесь очень помогли бы субсидии, подобные тем, что уже введены для разработчиков ЭКБ и аппаратуры.
В начале текущего года состоялась долгожданная встреча основных производителей печатных плат с Василием Викторовичем Шпаком, на тот момент директором Департамента радиоэлектронной промышленности Минпромторга России. Он пообещал нам, что рассмотрит наши предложения в отношении поддержки со стороны государства. Очень надеюсь, что будут приняты решения, которые помогут нам в финансировании расширения производств.

\section{Меры поддержкки отрасли, которые были введены за последнее время, к сожкалению, не охватывают таких участников процесса, как контрактные производства}

Что же касается гарантии заказов, мы ждем, когда заработает балльная система определения российскости радиоэлектронной аппаратуры. В текущей ситуации видится, что этот инструмент отчасти решит задачу защиты отечественных производителей, в том числе печатных плат. Дополнительные баллы - хороший мотив для заказчика разместить изготовление печатных плат в России, поскольку это защищает и его продукцию на внутреннем рынке.

Но представители Минпромторга неоднократно говорили о том, что в балльной системе будет сделан акцент на ключевую экБ - на процессоры, микроконтроллеры и т.п. Вы не боитесь, что печатные платы будут иметь настолько низкий вес в этой системе, что на них никто не будет обращать внимания?

Уже сам факт того, что производителю конечной продукции будет нужно набирать необходимые баллы тем или иным способом, открывает для нас, как для контрактного производства, определенные возможности. Так, заказчик может ждать появления подходящего по параметрам отечественного процессора, а пока его нет, добирать баллы за счет печатных плат.

Кроме того, ожидается, что балльная система будет со временем корректироваться; по мере развития отрасли будет повышаться порог для признания аппаратуры российской. Если окажется, что она не помогает производителям 
печатных плат, мы обратимся со своими предложениями в Минпромторг, и я уверен, что к нам прислушаются.

Сейчас главное, чтобы этот инструмент появился, а в дальнейшем его уже можно будет настраивать так, чтобы польза для промышленности от него была как можно более существенной. И подчеркну: для нас важно, чтобы такие меры работали на достаточно длительном отрезке времени, не сворачивались неожидан но. На строительство и запуск новой площадки по производству печатных плат уходит 3-4 года, и мы, инвестируя в свое расширение, должны быть уверены, что за это время условия кардинально не поменяются.

Если учесть, что новые мощности должны обладать определенной специализацией, хватит ли на нашем рынке заказов с соответствующей спецификой для их загрузки?

Да, сейчас ситуация на рынке такова, что существует большое количество заказов разных типов, но из-за нехватки мощностей или высокой цены изготовления в России значительная их доля размещается в азиатских странах.

В то же время здесь важно не создать излишней конкуренции между немногочисленными отечественными производителями печатных плат. Этот вопрос обсуждался и на упомянутой мной встрече. Планируется, что будет создано отраслевое сообщество, в рамках которого компании-производители распределят роли таким

\section{Даже если предположить, ито все активно работающие на рынке} компании - производители печатных плат вырастут в два раза, у них не хватит масштаба дяя прорыва

\section{в этой сфере}

образом, чтобы их мощности с учетом специфики отвечали запросам рынка. Это не только позволит более эффективно инвестировать в расширение производств и в дальнейшем их оптимально загружать, но и предоставит ориентиры для разработчиков, какие технологии закладывать в свои печатные платы, чтобы они могли без проблем изготавливаться в России.
Весной этого года в нашем журнале была опубликована ваша статья", в которой предлагался еще один путь развития производства печатных плат в России - строительство крупного завода. Эта идея может ужиться с тем, о чем вы говорите сейчас?

Безусловно. Создание такого завода - по сути, сквозной проект, который, как я писал в статье, поможет развиваться и таким небольшим компаниям, как наша.

Наверное, имеет смысл в общих чертах напомнить, в чем суть этой идеи.

Речь идет о том, чтобы создать большой завод по производству печатных плат, обслуживающий некоторое крупное предприятие, допустим КАМАЗ. Большие объемы производства данного завода потребуют налаживания поставок в Россию технологических материалов, комплектующих, оборудования и т. п. в оптовых количествах, за счет чего они станут в нашей стране дешевле. А со временем вокруг этого предприятия начнет формироваться экосистема из небольших компаний, которые будут брать на себя роль производителя этих материалов и комплектующих и заменять зарубежную продукцию отечественной.

Этот процесс можно сравнить с тем, как формировалась радиоэлектронная промышленность в Марий Эл вокруг Марийского машиностроительного завода, о чем я упоминал в начале нашего разговора.

Расширение существующих компаний - производителей печатных плат не может привести к такому эффекту?

Нет, для прорыва у них не хватит масштаба, даже если предположить, что все активно работающие на рынке компании вырастут в два раза.

Это можно для наглядности продемонстрировать на примере более простого производства - сборки по технологии поверхностного монтажа. Представьте, что у вас есть несколько десятков разбросанных по стране контрактных производителей с одной-двумя линиями у каждого, состоящими из оборудования различных вендоров. И в какой-то момент появляется крупный завод с десятками линий на одной площадке с сотней автоматов установки компонентов от одного поставщика. Очевидно, что именно

\footnotetext{
" См.: ЭЛЕКТРОНИКА: Наука, Технология, Бизнес. 2021. № 3.

С. 162-164.
} 
с появлением такого завода сначала возникнет мотив у производителя оборудования открыть рядом с ним свое представительство, затем производство комплектующих - тех же питателей, а со временем, возможно, создадутся условия и для того, чтобы российский инвестор заинтересовался организацией производства сначала комплектующих, а потом и оборудования для этого завода

А плодами этой экосистемы смогут воспользоваться и небольшие предприятия, работающие в своих нишах, потому что оборудование, оснастка, материалы и т. п. станут дешевле и доступнее.

Почему в качестве варианта основного заказчика для такого завода вы назвали КАМАЗ?

Конечно, это лишь пример. Но мне кажется, что крупное предприятие из автомобильной промышленности - наилучший кандидат на эту роль, потому что, с одной стороны, в современных автомобилях электроники становится всё больше, а с другой - у автопрома уже есть балльная система, а это еще одно основание для создания предприятия по производству печатных плат для собственных нужд на территории России.

Но безусловно, таким заказчиком может быть крупное предприятие и из другой отрасли, допустим, железнодорожной, нефтегазовой, телекоммуникационной

Кто, по вашему мнению, должен инвестировать в такой проект: сам будущий заказчик или государство?

Я думаю, это вопрос переговоров и более глубокого анализа. Вообще говоря, этот проект полезен и для государства, и для конкретного предприятия, которое будет его основным заказчиком. Для государства, потому что он создаст условия для развития производств и повысит степень локализации изготовления электроники, а, следовательно, усилит технологическую независимость страны, а для предприятия - потому что оно получит дополнительные преференции на внутреннем рынке.

А как правильно распределить инвестиции это уже вопрос к экономистам, которые обладают компетенциями для того, чтобы учесть все детали и реализовать эту идею наиболее близким к оптимальному способом.

Не вдаваясь в экономические тонкости, можно ли сказать, что такая глубокая локализация - вплоть до материалов и оборудования - в общем и целом оправдана? Ведь по модели международной кооперации работает множество компаний - мировых лидеров.

Локализация оправдана прежде всего тем, что она защищает от рисков. Пандемия COVID-19 показала, что в мире могут происходить совершенно неожиданные события. Страна, которая вам многие годы поставляла продукцию, может в одночасье прекратить поставки. И речь здесь не про санкции. У вас могут сохраняться прекрасные отношения с данной страной, а ваши изделия могут быть далеки от военной тематики. Просто в этой стране, например, сократятся объемы выпуска или, наоборот, вырастет производство конечной продукции, для которой нужны компоненты, поставляемые в том числе и вам, и для вас их будет не хватать.

\section{В технологической независимости} нет несущественных элементов. Вы не сможкете сделать устройство, если у вас нет нужного процессора, но вы также его не сделаете в отсутствие резистора, печатной
платы или даже простейщего провода

Во время первой волны пандемии к нам поступал просто шквал запросов, и мы были вынуждены отказывать, потому что были перегружены. Это происходило из-за того, что поставки печатных плат из Китая прекратились, а многие компании в России, которые специализируются на данной продукции, на самом деле не производят ее на собственных предприятиях в нашей стране, а заказывают в том же Китае. Данная ситуация - следствие негативной тенденции на российском рынке производства печатных плат последних лет: некоторые компании, которых и так было немного, закрылись, а иные переориентировались из производителей в брокеры. Это печально наблюдать, и я очень надеюсь, что в ближайшее время наступит перелом благодаря политике, проводимой Минпромторгом, тем мерам, которые уже действуют, и тем, которые мы так ждем от министерства.

Если это не сделать сейчас, потом может быть поздно. Ведь если у нас не будет собственных печатных плат, а с поставками из-за рубежа будут 
сложности, подобные тем, которые мы сейчас наблюдаем на рынке ЭКБ, у нас не будет электроники. В технологической независимости нет несущественных элементов. Вы не сможете сделать устройство, если у вас нет нужного процессора, но вы также его не сделаете в отсутствие резистора, печатной платы или даже простейшего провода, если у вас вышла из строя технологическая установка, а необходимых запчастей нет, или если закончился электролит для травления. Поэтому чем глубже локализация, тем безопаснее. И отрадно то, что руководство страны это понимает и уделяет этому большое внимание.

\section{В современном мире производитель должен рассматривать все новые решения, которые появляются в его отрасли, примерять их} на себя. В противном случае велика вероятность существенно потерять в конкурентоспособности

Ваша компания также стремится повысить глубину локализации: в уже упоминавшейся статье вы писали про налаженное в ООО «TEXНОТЕХ" производство фольгированных стеклотекстолитов, отмечая, однако, что препрег и фольга используются покупные. Есть ли движение в сторону локализации производства и этих материалов?

Действительно, на момент написания статьи мы использовали импортные препреги и фольгу. На их основе мы освоили производство двух видов стеклотекстолита - ML FR-4 и ML FR-4 HiTg с повышенной температурой стеклования.

Сейчас мы осваиваем производство ML FR-4 с использованием препрегов, выпускаемых Бобровским изоляционным заводом. Ждем, когда появится фольга от Кыштымского медеэлектролитного завода - это должно произойти в самое ближайшее время, и тогда мы сможем изготавливать по крайней мере стеклотекстолит FR-4 полностью из отечественных материалов. По всей видимости, он будет дороже материала из импортных препрега и фольги, потомучто выигрыш на логистике не компенсирует более высокие цены отечественных производителей, связанные с малыми объемами выпуска. Но переход на российские материалы позволит нам лучше контролировать качество и сроки производства, избегать тех рисков срыва или задержек поставок материалов из-за рубежа, которые себя проявляют в нынешней ситуации. Ведь если раньше срок поставки препрега из Китая составлял один-полтора месяца, то сейчас он вырос до трех-четырех.

Так что ответ на ваш вопрос об увеличении глубины локализации изготовления стеклотекстолитов положительный.

В заключение нашего разговора хотелось бы узнать ваше мнение о таких новых технологиях в производстве печатных плат, как 3D-печать, прямое формирование рисунка, селективное нанесение паяльной маски - словом, о тех решениях, которые призваны упростить и ускорить изготовление прототипов и малых серий.

Это действительно интересные технологии, и мы следим за их развитием. Вообще, в современном мире производитель должен рассматривать все новые решения, которые появляются в его отрасли, примерять их на себя. В противном случае велика вероятность пропустить что-то важное и существенно потерять в конкурентоспособности.

Если говорить про 3D-печать плат, это очень многообещающая технология, но пока расходные материалы для нее дороги, что ограничивает ее применение в реальном производстве. Тем не менее, у нас недавно стартовал совместный проект с одним из вузов по созданию учебной лаборатории, охватывающей полный цикл производства печатных плат, и там будет использоваться 3D-принтер, потому что для учебных целей это очень хорошее решение, перекрывающее целый ряд производственных операций, организация которых в учебном заведении в традиционном виде нецелесообразна.

Кстати, я упомянул бы еще одну 3D-технологию, внедрение которой в России, на мой взгляд, было бы очень полезно. Это технология 3D-MID. Мы давно к ней присматриваемся, и не исключаю, что в перспективе освоим ее на нашем производстве

Так что мы следим за различными решениями, инновациями и развитием технологий с тем, чтобы расширять сферу своей деятельности и идти в ногу со временем.

Спасибо за интересный рассказ.

С В.Д. Семёновым беседовал Ю. С. Ковалевский 


\section{EXPO ELECTRONICA}

24-я Международная выставка электронных компонентов, модулей и комплектующих

\section{expoelectronica.ru}

ЗАБРОНИРУЙТЕ СТЕНД на ExpoElectronica

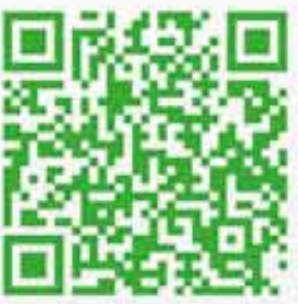

12-14 апреля 2022

Москва, Крокус Экспо

\section{1) ELECTRON}

19-я Международная выставка

технологий, оборудования и материалов для производства изделий электронной и электротехнической промышленности

electrontechexpo.ru

\section{ЗАБРОНИРУЙТЕ СТЕНД} на ElectronTechExpo
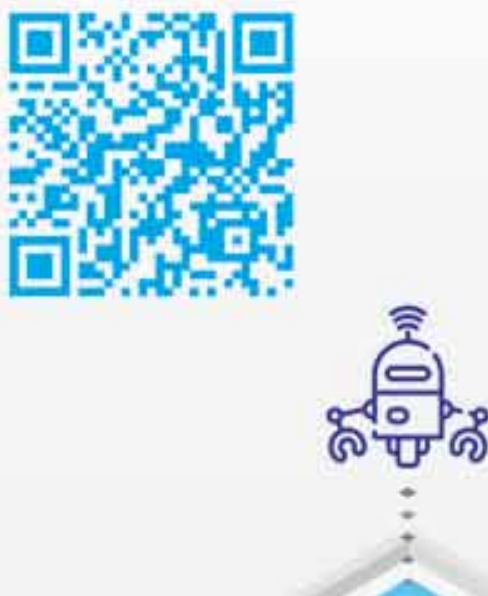